\title{
EDUCAÇÃO CIENTÍFICA E REALIDADE AGROPECUÁRIA EM CUBA: ALGUMAS IDEIAS SOBRE SUA MUDANÇA EPISTEMOLÓGICA
}

\author{
EDUCACION CIENTIFICA Y REALIDAD AGROPECUARIA EN CUBA: ALGUNAS \\ IDEAS SOBRE SU CAMBIO EPISTEMOLÓGICO
}

\author{
SCIENTIFIC EDUCATION AND AGRICULTURAL REALITY IN CUBA: SOME IDEAS \\ ABOUT THE EPISTEMOLOGICAL REVOLUTION
}

\author{
Eduardo Francisco Freyre ROACH ${ }^{1}$ \\ Adolfo Ramos LAMAR ${ }^{2}$
}

RESUMO: Este artigo aborda a mudança epistemológica que hoje vem ganhando importância no contexto da Educação Superior agropecuária de Cuba. Significa que nesse contexto vai se abrindo uma nova visão do conhecimento científico, sua ontologia, gnosiologia, lógica, método e sua relação com a tecnologia e com o conhecimento dos camponeses, assim como seus condicionamentos e impactos sociais e ambientais. Esta mudança de paradigma epistemológico está relacionada com a necessidade do desenvolvimento sustentável da agricultura como alternativa ao modelo convencional de desenvolvimento agropecuário apoiado na monocultura, na dependência de altos insumos industriais importados e a prática de extensionismo agrário vertical-burocrático das instituições de produção de conhecimentos científicos. $\mathrm{O}$ estudo foi elaborado mediante a revisão bibliográfica-documental e a sistematização da experiência docente e de pesquisa dos autores no campo da filosofia, a epistemologia e a metodologia da pesquisa em educação.

PALAVRAS-CHAVE: Agricultura sustentável. Cuba. Educação superior agropecuária. Epistemologia.

RESUMEN: Este artículo aborda el cambio epistemológico que hoy en día hoy se observa en el contexto de la investigación y educación científica superior agropecuaria de Cuba. Significa que en este contexto se va abriendo paso una nueva visión del conocimiento científico, su ontología, gnoseología, lógica, y método, su relación con la tecnología y el conocimiento de los campesinos, así como sus condicionamientos e impactos sociales y ambientales. Este cambio de paradigma epistemológico guarda relación con la necesidad del desarrollo

${ }^{1}$ Universidade Regional de Blumenau (FURB), Blumenau - SC - Brasil. Pós-doutorado em Educação pela Universidade Estadual de Campinas (2007). Doutorado em Ciências Filosóficas pela Universidade Estadual Mijail Lomonosov, Rússia, (1989). Mestrado em Estudos de Budismo por la Universidad de Hong Kong (HKU, 2014). Licenciatura em Filosofia e Mestrado em Filosofia pela Universidade Estadual Mijail Lomonosov de Moscou (MGU, 1983). Foi Professor Titular da Universidade Agraria de la Habana, Cuba. Pesquisador do Grupo de pesquisa Educogitans da ORCID: <https://orcid.org/0000-0002-2267-1564>. E-mail: freyre.roach2016@gmail.com

${ }^{2}$ Universidade Regional de Blumenau (FURB), Blumenau - SC - Brasil. Docente. Doutorado em Educação (1998) e mestrado em Política Científica e Tecnológica pela Universidade Estadual de Campinas (1995), pós-doutorado em Educação pela Universidade de São Paulo (2007), Brasil e Licenciatura em Filosofia pela Universidad de la Habana (1982). Pesquisador do Grupo de Pesquisa Educogitans da FURB. ORCID: <https://orcid.org/0000-00031164-1172>. E-mail: jemabra@furb.br

RIAEE - Revista Ibero-Americana de Estudos em Educação, Araraquara, v. 14, n. 3, p. 928-941, jul./set., 2019. e-ISSN: 1982-5587. 
sostenible de la agricultura como alternativa al modelo convencional de desarrollo agropecuario centrado en el monocultivo, la dependencia de altos insumos industriales importados y la practica de extensionismo agrario vertical-burocrático de las instituciones de producción de conocimientos científicos. El estudio contempló revisión bibliográficadocumental y sistematización de la experiencia docente e investigativa de los autores en el campo de la filosofía, la epistemología y la metodología de la investigación en educación.

PALABRAS CLAVE: Agricultura sostenible. Cuba. Educación científica. Epistemología.

ABSTRACT: This article addresses the epistemological revolution that today is observed in the context of research and higher agricultural science education in Cuba. It means that in this context a new vision of scientific knowledge, its ontology, theory of knowledge, logic, and method, its relationship with technology and the knowledge of the peasants, as well as its social and environmental conditions and impacts, is taking place. This change of epistemological paradigm is related to the need for the sustainable development of agriculture as an alternative to the conventional model of agricultural development centered on the cultivation, dependence on imported high industrial inputs and the practice of vertical-bureaucratic agrarian extension of production institutions of scientific knowledge. The study included bibliographicdocumentary review and systematization of the teaching and research experience of the authors in the field of philosophy, epistemology, and the methodology of educational research.

KEYWORDS: Sustainable agriculture. Cuba. Scientific Education. Epistemology.

\section{Introdução}

Os profissionais das ciências, tecnologias e engenharias agropecuárias realizam seu trabalho, assumindo pressupostos epistemológicos, ou seja, certa visão da natureza do conhecimento científico, sua ontologia, gnosiologia, lógica, método, sua relação com a tecnologia e com o conhecimento dos camponeses, bem como seus condicionamentos e impactos sociais e ambientais. Assim, destacamos que para Gamboa (2013, p. 77) a "Epistemologia significa literalmente teoria da ciência".

Por fatores intra-exta acadêmicos, tem progredido o debate epistemológico no ensino superior agropecuário cubana. Um é sem dúvidas que a atividade de ciência e tecnologia, dado o seu nível de sofisticação e oportunidades que lhe concedem para seu desenvolvimento e suas aplicações, assim como o impacto ambiental e sociocultural, está obrigando a repensar qual há de ser o rumo atinado da produção de conhecimento, sua lógica, método e, assim, sua pertinência.

Outro é que o modelo de desenvolvimento agropecuário convencional de Revolução Verde, tem feito acompanhar uma imagem do conhecimento e da realidade que limita o potencial gnosiológico da ciência e da tecnológica, e, como se fosse pouco, condiciona os 
impactos sociais, econômicos e ambientais que urge resolver. Obviamente, o enfoque do desenvolvimento sustentável da agricultura que tem mostrado ser a alternativa viável para erradicar estes problemas, oferece e demanda a superação dos vieses epistemológicos da Revolução Verde.

Finalmente, como se bem sabe, a reflexão epistemológica já não é a mesma que há de 40 ou 50 anos atrás. Múltiplas perspectivas epistemológicas interceptam a imagem clássica ou convencional da natureza e do conhecimento científico e tecnológico que, como bem se conhece, se fundamenta na filosofia moderna e no positivismo.

Neste trabalho abordamos a mudança epistemológica que, de acordo com os fatores mencionados, vai cobrando amplitude e intensidade nas ciências agropecuárias em Cuba, a partir do final dos anos 80. Proporcionamos um enfoque acerca da reimplementação de problemas epistemológicos à luz deste acontecimento e os fatores condicionantes levando em conta a revisão de literatura e documentação e nossa experiência como professores e pesquisadores.

\section{Epistemologia e Educação científica}

Os cientistas em geral, e os que contribuem com a produção agropecuária e industrial de alimentos em particular costumam estar motivados e:

[... ] capacitados no uso de estudos experimentais e de observação para gerar informações confiáveis sobre o mundo, estes estudos se utilizam frequentemente para informar decisões pessoais, comerciais e políticas sobre como atuar na sociedade. No entanto, a distinção entre as declarações sobre como é o mundo e a decisão mais ampla sobre o que as pessoas deveriam fazer na sociedade no que se considera comum na formação científica e, muitas vezes, não é apreciada pelos próprios cientistas... Não se costuma apreciar entre muitos cientistas que as decisões práticas que surgem de seus experimentos (por exemplo, "este produto químico é seguro") implica tanto dados empíricos como valores sociais (CHILES; NEIL, 2017, p. 1).

A questão supracitada tem relação com as considerações de índole epistemológica que adotam os profissionais da pesquisa e do ensino de ciências agropecuárias. Por exemplo, onde se assumia que as ciências deveriam produzir exclusivamente um conhecimento objetivo, racional e nomotético de processos naturais, obviamente, se fecha a consideração dos valores na hora de suscitar o problema da pesquisa, e a escolha dos métodos e técnicas para a coleta da informação, seu processamento, valorização e introdução prática e monitoramento de seus impactos. 
Certamente ocorre que os cientistas envolvidos na produção de alimentos agropecuários não se dão conta em alguns momentos da necessidade de repensar a relação entre as observações científicas, as decisões práticas, e o que pensa o agricultor e o cidadão comum e corriqueiro. Quando percebem que os resultados de suas pesquisas não se aplicam ou são rechaçados, transferem este "cinismo público" ao "déficit de informação" e aos costumes equivocados sobre o conhecimento (BESLEY; NISBET, 2011, p. 2). Esta atitude se observa a partir do paradigma epistemológico contempla que os resultados científicos por definição superam sempre os conhecimentos dos agricultores e, cedo ou tarde e incondicionalmente, hão de ser sujeitos de propagação, aplicação, difusão e transferência.

Nós que investigamos a epistemologia das ciências agropecuárias e realizamos o trabalho docente também não estamos isentos dos mesmos vieses. $\mathrm{E}$ isso ocorre muito frequentemente onde a pesquisa e a docência da epistemologia seguem a mesma imagem de cientificidade que adotam os profissionais das ciências naturais e biotecnológicas (MILLER, 2006).

Se olhamos o assunto a partir da perspectiva que sugere Jürgen Habermas (1982) em seu livro Knowledge and Human Interests, não surpreende que não haja trabalhos em ciências da educação agropecuária, incluindo os de epistemologia, pegos no paradigma do empirismo positivista. Por outro lado, hoje se convida a produzir conhecimentos na educação científica agropecuária de interesse interpretativo, crítico e emancipador, um saber direcionado a questões normativas e axiológicas, que buscam a través da interdisciplinaridade, novos caminhos para o conhecimento, método e compreensão (DYER; HASSE-WITTLER; WASHBURN, 2003)³. Ou seja, também se trata de um desafio analítico prescritivo-pragmático (versus especulativo) que se projete para além de prescrever recursos ou estratégias de ensino-aprendizagem, e que atenda questões sobre a natureza conhecimento científico agropecuário, assim como sua divulgação, e suas múltiplas aplicações, benefícios e riscos (LOVE, 1978).

Enfim, nosso trabalho se situa no entrecruzamento dos campos de reflexão epistemológica. Um é o que nos propomos a denominar "epistemologia das ciências agropecuárias" e o do outro da "epistemologia da educação em ciências agropecuárias. As enxergamos com duas esferas diferentes quanto a seu objetivo e diferente, mas conectadas e confluentes e que contribuem com a necessidade perene de repensar a ciência e a tecnologia.

${ }^{3}$ Alguns autores têm realizado pesquisas neste sentido. Por exemplo, o estudo que demonstra que a maioria das pesquisas em educação agropecuária utilizam esta perspectiva empirista (Dyer; Hasse-Wittler; Washburn; 2003). 


\section{A mudança epistemológica que sugere e demanda o enfoque agroecológico de desenvolvimento sustentável da agricultura cubana.}

Em que consiste e que fatores intervêm na mudança de paradigma epistemológico que se observa hoje no contexto de pesquisa e docência em ciências agropecuárias em Cuba? Vejamos.

O estado cubano, como outros estados, apostou no modelo de agricultura de Revolução Verde, ou de altos insumos como diretriz tecnológica da política de desenvolvimento agropecuário. Se apoiou nos acordos bilaterais da década de 70 com a ex União Soviética ou a URSS e devido à condição de Cuba como membro permanente do Conselho de Ajuda Mútua e Econômica (CAME). Este é um fator que condicionou não só as políticas econômicas agropecuárias, mas também as de ciências, tecnologias e inovação tecnológica, assim como as de educação científica e cultura.

Graças a esta escolha Cuba conseguiu manter os subsídios dos fertilizantes, pesticidas e combustíveis para os agricultores. Vale destacar que até o final dos anos 80 é dependente sobremaneira altos insumos industriais exógenos. Como se sabe, a intensidade do uso de fertilizantes e tratores chegou a ser similar e maior que a dos países desenvolvidos na Europa e Estados Unidos. É verdade que a implementação do modelo convencional de agricultura de Cuba alcançou:

[...] aumentos substanciais quanto à quantidade de terras empregadas na produtividade da força de trabalho, mas a um custo proporcional em insumos adquiridos a preços subsidiados... Inclusive, o emprego de tecnologias custosas e de altos insumos não alcançou as expectativas e teve impactos ambientais negativos [...] (FUNES-MONZOTE, 2010, p. 6). ${ }^{4}$

Já no final dos anos 80 se detectaram severas afetações dos solos e da baixa produtividade agrícola. Nesta conjuntura apareceu, nas universidades cubanas, um movimento de professores preocupados com o problema ambiental e empenhados em encontrar soluções inspiradas na ecologia e o saber agrícola tradicional. Forma-se no Complexo CientíficoDocente Universidade Agrária de Havana (UNAH) e Grupo Gestor da Associação Cubana de Agricultura Orgânica (ACAO), que, ainda que seu projeto de se constituir em uma Organização Não-Governamental não encontrou aprovação oficial, sua influência na pesquisa e no currículo

${ }^{4}$ [...] incrementos sustanciales en cuanto a la cantidad de tierras empleadas y la productividad de la fuerza de trabajo, pero a un costo proporcional en insumos adquiridos a precios subsidiados...Incluso, el empleo de tecnologías costosas y de altos insumos no alcanzó las expectativas, y tuvo impactos ambientales negativos [...] (FUNES-MONZOTE, 2010, p. 6). 
se fizeram sentir imediatamente desde então. Hoje em dia o que era a ACAO opera como Grupo de Agricultura Orgânica (GAO) anexo à Associação Cubana de Técnicos Agrícolas e Florestais (ACTAF).

Portanto, o colapso do socialismo euro-soviético em 1990 foi difícil para Cuba. Interrompem-se abruptamente as importações de insumos e maquinarias agropecuárias. Ao mesmo tempo, a administração republicana Georg Bush nos Estados Unidos intensifica o bloqueio econômico que se impôs a Cuba em 19615. Como resultado, os projetos de desenvolvimento agropecuário baseados no enfoque da agricultura convencional da Revolução Verde ficam no meio de caminho. Se reduzem as importância e exportações, assim como a cesta básica de recursos e alimentos subsidiados.

Uma medida crucial para enfrentar a crise foi a descentralização da posse da terra. $\mathrm{O}$ predomínio do setor estatal ( $85 \%$ da posse da terra) chega ao fim ${ }^{6}$. O slogan "A terra para quem trabalha! " merece atualização, ainda que para alguns se trate de uma $3^{\text {a }}$ Lei de Reforma Agrária. Simultaneamente vêm a descentralização do mercado agropecuário e o fomento do desenvolvimento endógeno e local. Nesta conjuntura também se reorganiza o sistema de ciência e inovação tecnologia (SCIT). O ideal de maior especialização, integração e aplicação das conquistas em ciência e tecnologia (sobretudo biotecnológicos) incorporou no sistema de Polos Científicos-Tecnológicos (PCT). Se mantém o sistema dos subsídios para o acesso dos produtores a fertilizantes e pesticidas químicos e combustíveis. Contudo, apesar do ideal da Revolução Verde não ter sido abandona, assumindo-se romântico e nostálgico, se adota e se referenda o enfoque da Agricultura Sustentável como diretriz tecnológica fundamental da política agrícola ${ }^{7}$ e a entrega de terras ${ }^{8}$.

Há uma ampla documentação nacional e internacional sobre o rumo da Agricultura Sustentável em Cuba, suas conquistas e desafios (FUNES MONZOTE et al., 2001, FUNES MONZOTE, 2010; CHAN; FREYRE, 2012). Neste caso, a adoção da agricultura sustentável

\footnotetext{
${ }^{5}$ Estas leis referendam a imposição de sanções a empresas que estabeleceram acordos comerciais com Cuba. Esta projeção extraterritorial fecha as portas de aceso a recursos e créditos a Cuba

${ }^{6}$ O Estado emitiu em 1993 um Decreto Lei n. 142 que entrega a "posse" de usofruto gratiuto (não de propriedade) um \% considerável de suas terras estáveis, a coletivos trabalhadores que trabalham nas empresas estatais. Emergiram assim as chamadas Unidades Básicas de Produção Cooperativa (UBPC). Depois, viera o Decreto n. 259 de 2008 sobre a entrega de terras ociosas, que outorga posse de terra em usufruto a todo aquele que queira produzir alimentos agropecuários, tanto no campo como no meio urbano.

${ }^{7}$ Em correspondência com a Agenda 21, Lei no. 81 do Meio Ambiente, ditada pelo Ministério da Ciência, Tecnologia e Meio Ambiente (CITMA), estimula o fomento da Agricultura Sustentável, quer dizer, da produção de 2008 sobre a entrega de terras ociosas estipula que novos donos estão obrigados a realizar práticas de agricultura sustentável nas terras que se entreguem em usufruto.

${ }^{8}$ Decreto no. 259 de 2008 sobre a entrega de terras ociosas estipula que novos donos de terras estejam obrigados a realizar práticas de agricultura sustentável em que as terras que lhes sejam entregues por usufruto.
} 
e seu escalonamento no currículo das universidades e faculdades agropecuárias em Cuba sugerem e demandam uma recolocação da epistemologia e das ciências agropecuárias, quer dizer, da sua ontologia, gnosiologia, lógica, métodos, etc.

Nota-se em primeiro lugar que a agricultura de monoculturas em razão da indústria e das exportações, se supõe que a terra e os ecossistemas possam ser gerenciados como se gerenciam mesmo os processos da indústria em um ambiente, e onde você pode controlar variáveis. Por isso que entra em jogo seu papel aqui a imagem de um conhecimento cujo objeto são processos mecânicos, e que busca a artificialização e exploração tecnológica ao máximo dos ecossistemas. Quer dizer, que se tenderá a ver a natureza só enquanto se os processos mecânicos. Este seria o pressuposto epistemológico que subsidia a investigação agraria convencional, sobretudo quando se multiplicam as investigações sobre a efetividade o rendimento de uma semente, uma fórmula de fertilizante ou pesticida, uma monocultura, de gado, etc. Uma análise das pesquisas que se realizavam nas universidades agrárias de Cuba até 1990 poria esta ontologia agrícola a ser descoberta. No entanto, não tem a ver mais que até esta data os planos quinquenais de desenvolvimento agropecuária davam predominância aos cultivos que contribuem com a indústria e a exportação: cana, café, tabaco e cítricos.

Somamos a isso o desenvolvimento de monoculturas, além de dar preeminência à atomização do objeto de conhecimento, a superespecialização, o conhecimento de laboratório ou em estações experimentais, de fato, supõe uma ruptura ou dualismo natureza-sociedade. Ou, talvez seja melhor dizer, que tal relação se vê reduzida à decisão sobre artificialização do ecossistema, onde aos experientes ou especialistas lhes endossa o protagonismo epistemológico. Neste sentido, as decisões de conhecimento e sua aplicação, se adotam centralizadas e burocraticamente, o qual se reflete muito bem o sistema tácito de extensionismo linear, vertical, ofertista, paternalista e transferencista e com enfoque technology-push, através de pacotes tecnológicos, baseados no uso intensivo de insumos (LÓPEZ TEODORO, 2005).

E como veremos mais tarde, este viés epistemológico contempla a estigmatização, marginalização e exclusão do saber agricultor. Quer dizer, que o saber agricultor não se contempla e as decisões de produção dos conhecimentos. A significação ontológica que isso tem é que a realidade agropecuária enquanto objetivo só se percebe em razão do que o método científico pode mostrar. Cultivos e ecossistemas que encaixe neste modelo de fazer ciência, não fazem parte da ontologia do saber agropecuário.

O enfoque agroecológico da agricultura sustentável impõe uma nova visão da ontologia do conhecimento científico agropecuário, pois implica repensar o problema da realização natureza-sociedade e a natureza do conhecimento agropecuário mais além da lógica do 
Marxismo-Ortodoxo e o Neoliberalismo (LEFF, 2011, p. 135). Sendo o objetivo preferencial o ecossistema o agroecossistemas, se faz patente que a realidade agropecuária ultrapasse o dualismo epistemológico.

Isso sugere, como bem destacam os autores, a reivindicação de enfoque sistêmico e holístico, a superação de atomismo, o mecanismo, o universalismo, o objetivismo e o monismo assim como a potencialização do trabalho interdisciplinar e transdisciplinar e a necessidade de “introspecção dos saberes camponeses” (BORSATTO; SIMÕES DO CARMO, 2011, p. 9).

A partir de 1990, em Cuba, o escalonamento da agricultura sustentável e o enfoque agroecológico oferece diversos exemplos onde essa epistemologia se coloca à prova. Por exemplo, em Cuba cabe destacar o enfoque "de camponês a camponês" (CAC) (MACHIN et al., 2010, p.1) e o do Programa de Inovação Agropecuária Local (PIAL) do Instituto Nacional de Ciências Agrícolas (INCA) da UNAH, com enfoque de Fitomelhoramento Participativo (FP). Em ambos programas que se desenvolvem em todo o país se trabalha em agroecossistemas de policulturas (versus monoculturas), com insumos locais endógenos, e a pesquisa e as decisões onde os camponeses, os pesquisadores e o pessoal administrativo trabalham cooperativamente, sendo suas interações de forma horizontal (versus vertical e burocrática).

\section{Algumas implicações da mudança na educação epistemológica agropecuária de Cuba}

Agora veremos que esta nova visão da ciência e tecnologia vem se abrindo ao passo que também na mudança de planos e programa de estudos, mas em especial nas mudanças da docência relacionada com a teoria da ciência e da tecnologia.

No começo dos anos 90, ocorreu a introdução da disciplina Problemas Sociais das Ciências e Tecnologias (PSCT). Neste processo se manifestaram os ares que sopravam na nossa academia de integração dos conhecimentos e interdisciplinaridade, bem como na necessidade de um ensino do Marxismo sem viés de manualismo, dogmatismo e vulgarização. Por outro lado, que os cursos contribuíram com os perfis profissionais específicos, não só quanto a formação humanista geral, ideológica e sociopolítica, mas também metodológica, técnica e prática.

Com a perestroika primeiro e depois o colapso da URSS e do campo socialista em 1990, se pensa com mais intenso ensino de um Marxismo que atendesse às demandas do contexto terceiro-mundista e cubano, as realidades e tradições de pensamentos.

Contudo, qual é a revolução epistemológica que vem se abrindo associada às transformações do ensino da Filosofia? Pesquisas que realizamos no começo dos anos 90 sobre 
a docência da Filosofia no Ensino Superior em Agropecuária constatam que enquanto nas aulas de Filosofia insistíamos na dialética entre o empírico e o teórico e o contraponto com o empirismo e o Positivismo, os textos dos cursos de perfil agropecuário colocavam ênfase no sensorial e no empírico, em razão das propostas dos chamados "pacotes tecnológicos". A apologia à observação, a experimentação e a lógica indutiva constituíam os pilares em que se suportava a investigação agropecuária no nosso Instituto Superior de Ciências Agropecuárias $(\text { ISCAH })^{9}$, hoje Complexo Científico Docente Universidade Agrária de Havana (UNAH).

A partir de 7 de setembro de 1976 (data de fundação da ISCAH) e durante a década de 80, o Departamento de Agroquímica possuía grande relevância e, claro está pautado em grande medida na epistemologia da pesquisa agropecuária em geral e corresponde aos planos económicos quinquenais de desenvolvimento agrícola e industrial dos Ministérios da Agricultura (MINAG) e do açúcar (MINAZ). Não faz falta aqui discorrer em qual pilar chave destes planos era a importação de $90 \%$ insumos químicos e maquinarias provenientes da então URSS.

A produção e aplicação do chamado pacote tecnológico de fertilização à base de Nitrogênero, Potássio e Carbono (NPK) nos diferentes cultivos (tomate, batata, milho, cana de açúcar, etc) se baseava no método standard inspirado na conhecida "tabela da indução" (tabula presentiae, tabula absentiae, tabula graduum) proposta pelo filósofo moderno Francis Bacón. Tal modelo de investigação costuma ter grande aplicação também quando se quer saber o rendimento potencial de uma variedade de sementes ou de um praguicida.

Recordemos que para F. Bacon tal proceder garante que você se eleve ao conhecimento da lei e do conceito universal do que se pesquisa e cautelosamente se evitem assim as deduções apriorísticas arbitrárias. O procedimento indutivo na forma que o sistematiza Bacon em sua Novum Organum dde 1620, as regras do método de René Descartes (1806-1873) assim como os métodos da indução (concordância, diferenças, resíduos e variações concomitantes) de John Stuart Mill (1806-1873) pautaria a epistemologia da pesquisa agropecuária, contribuindo com a assistida pelo governo artificialização e homogeneização dos agroecossistemas, em razão da produção em enormes extensões de monoculturas, o alto uso de insumos externos e a transferência tecnológica.

A crítica a Bacón, Descartes e o positivismo ficou um bom tempo estacada dentro destes limites e, até certo ponto, opacada pela influência oculta destes referentes epistemológicos nas

\footnotetext{
9 Pauta este processo a Lei no. 1307-1976 (sobre o estabelecimento da estrutura por especializações em correspondência à planificação do desenvolvimento econômico e social). Como resultado, a educação agropecuária adquiriu uma configuração independente das universidades.
} 
atividades de pesquisa e docência correspondente ao perfil dos cursos agrários. Isso fortaleceria a assunção dualística da ruptura epistemológica entre ciências naturais e engenharias e ciências sociais. Não é difícil compreender que isso leva a reprodução da imagem clássica da ciência e o conhecimento que vem com Bacón, Descartes, Newton, Galileo e o Postivismo. E neste contexto, vieses empiristas e positivistas formavam parte da agenda epistemológica da pesquisa agrária: automatização do objeto ${ }^{10}$; culto ao conhecimento científico, estigmatização e exclusão do saber camponês tradicional; o tecnocratismo e a burocratização; assim como um regime de extensão agrária verticalizado, hierárquico, patriarcal, transferencista e ofertista e com enfoque de impulso tecnológico (technology-push), da qual falamos anteriormente.

Havia um divórcio entre as pesquisas agropecuárias do laboratório ou estações experimentais, ciências naturais e engenharias e as ciências sociais. Em nossa universidade agrária teve mais relevância o debate acerca de como a Epistemologia poderia colaborar com o perfil agropecuário, sem necessidade de vulgarizá-la. Eram tempos em que o cientificismo e o tecnocratismo se argumentavam nos conteúdos que trabalhávamos nos cursos agropecuários acerca da ciência e da tecnologia e predominava a superespecialização cognoscitiva, prática, institucional e curricular.

Ao final dos anos 90, foi aprovado pelo Ministério da Educação Superior (MÊS) que as aulas de Filosofia se desenham a partir das necessidades da formação profissional por cada um dos cursos. Naquele momento então adquiriu auge o debate sobre a necessidade de maior vinculo da Filosofia com o perfil dos cursos agropecuários sem cair na vulgarização nem "perfilização" 11

E então, como se disse, que entrando nos anos 90 ocorre uma transformação de conotação epistemológica importante: a introdução do curso de Problemas Sociais da Ciência e Tecnologia (PSCT). Neste campo se integraram estudos que já se vinham fazendo na URSS, em Cuba e outros países sobre problemas filosóficos das ciências naturais e Cienciologia ((FIGAREDO CURRIEL, 2002). Nós, autores deste artigo, e outros colegas, já vínhamos trabalhando com os trabalhos de B. Kedrov sobre a classificação das ciências, os trabalhos de John Bernal (1986) sobre a história social das ciências, de Mario Bunge, León Olive, assim como de Mikulinski e outros filósofos, sobre a teoria e metodologia do conhecimento científico. Professores de disciplinas sobre as concepções de Ciência e Tecnologia exploravam

10 “Ao negar a existência de sujeito epistêmico (o investigador é considerado um mero catalogador de fenômenos), o empirismo colocou exagerada importância nas regras metodológicas, ao ponto de chegar a uma espécie de absolutização normativa" (GOMEZ, 1999, p. 35).

${ }^{11}$ Palavra que se utilizava muito entre nós no ensino superior agropecuário cubano. 
instantemente temas de política científica na América Latina e Caribe, estudando obras de Amílcar Herrera, Jorge Sabato, Oscar Varsavsky, José Leite Lopes, Miguel Wionczek, y Francisco Sagasti, etc. Nos eram alheias aquelas propostas epistemológicas de rebeldia antipositivistas nos trabalhos de cientistas e filósofos contemporâneos. Cabe destacar aqui o Pós-Positivismo (Popper, Fleck, Kuhn, Lakatos, Feyerabend, etc.), assim como a Fenomenologia e a Hermenêutica (Husserl, Heidegger, Gadamer), a Filosofia Crítica (Adorno, Horkheimer, Habermas), Foucault e Derrida e o Pensamento da Complexidade (Prigogine, Varela, Humberto Maturana, Edgar Morin). Nas faculdades de engenharias começaram a se conhecer contribuições, a Sociologia e a Ciência, a Filosofia da Tecnologia (Kapp, Mumford, Bunge, Ellul, Mitcham, etc.).

A internacionalização crucial do curso de PSCT em todos os cursos universitários é até então potenciar uma educação científica que supere as "imagens obsoletas (lineares, simplificadas e otimistas) da ciência e tecnologia, objetividade e a verdade" (NÚÑEZ JOVER, 2001, p.5). O curso de PSCT que se oferece até hoje em dia na UNAH segue esta pauta (FREYRE; LAMAR, 1994). Portanto, compartilhamos a opinião de Jacob (2016) de que "Falar hoje sobre agroecologia não causa tanto estranhamento quanto há 15 anos..."

\section{Considerações finais}

Hoje em dia, dadas as múltiplas propostas de epistemologias que desafiam a epistemologia convencional, se repensa o problema de que se ao final se irá impor um paradigma epistemológico (monismo) ou conviverão muitos (pluralismo) (GOMES, 1999). A “abertura epistemológica e metodológica na produção do conhecimento", ao mesmo tempo desfaz a "concepção tradicional sobre ciência e a considera como uma atividade autônoma, valorativamente neutra e benfeitora da humanidade".

No entanto, outros autores apostam que a Agroecologia elabore sua própria epistemologia (SERRA BORSATTO; SIMÕES DO CARMO, 2012). Somos da opinião que tudo depende nem tanto da dinâmica da comunidade científica. Em nossa instituição agropecuária ocorre o mesmo que já previa Thomas S. Khun (1978), quer dizer, que há um período em que os cientistas exploram diferentes paradigmas. Mas o mais sobressalente em nossa opinião é que há tensões epistemológicas no ensino superior agropecuário cubano.

O enfoque da agricultura sustentável está adquirindo relevância em nossas instituições de educação agropecuária, mas não é menos certo que há apoio a técnicas que encaixam com a epistemologia da agricultura convencional. A partir daí que inclusive os que apoiam a modificação 
genética de organismo, em geral, costumam dizer, alguns o desenvolvimento da agricultura sustentável é conjuntural dada à escassez de recursos para leva-la a cabo. Outros optam por dizer, que a agricultura transgênica e outras como a agricultura de precisão podem sem compatíveis com o enfoque agroecológico, o que ambos métodos podem se integrar. Muitos definem o tratamento integrado de pragas (MIP) nesta mesma direção, quer dizer, combinando o controle biológico (uso de inimigos naturais das plantas) e o controle químico convencional. E não falta quem proponha combinar fertilizantes químicos e orgânicos, ou tratamento de monoculturas com enfoque de agricultura sustentável.

Há aspectos da produção agropecuária que não se revelam na percepção direta, quer dizer, sensorialmente: como a diminuição das taxas de perda de solo e nutrientes, os níveis de microrganismos benéficos do solo e as reduções na quantidade de produtos químicos que se filtram no lençol freático. Esta tensão entre o "visível" e o "não visível" adquire importância no debate epistemológico sobre a agricultura sustentável e a convencional.

A repercussão epistemológica que vem tendo o curso de PSCT nas universidades cubanas e, por fim, no ensino superior agropecuário se expressa também em que conteúdos resultam requisitos para a mudança de categorias docentes (Professor assistente, auxiliar e titular) e científicas (pesquisador agregado, auxiliar e titular) e para optar pelo Grau Científico de Doutor em todas as especialidades científicas. Simultaneamente, vemos que professores de Filosofia começam a se inserir nos temas de pesquisa agropecuária e professores de ciências agropecuárias participam em pesquisas sobre questões filosóficas, ético-profissionais, econômicas e políticas relacionadas sobretudo com seu perfil profissional e de trabalho.

\section{REFERÊNCIAS}

BERNAL, J. D. Historia Social de la Ciencia. 1. y 2. partes. Editorial de Ciencias Sociales. La Habana, 1986.

CAROLAN, M, S. Do You See What I See? Examining the Epistemic Barriers to Sustainable Agriculture. Rural Sociology, v. 71, n. 2, p. 232-260, jun. 2006. DOI: https://doi.org/10.1526/003601106777789756.

CHILES, R.; NEIL, C. Questioning Reality, Questioning Science: Teaching Students in the Food and Agricultural Sciences about Epistemological, Ethical, and Empirical Controversies”. Wiley Online Library. First published: 03 April 2017, p. 1. DOI: https://doi.org/10.1111/1541-4329.12106. 
COSTA GOMES, J. C.; ROSENSTEIN, S. A geração de conhecimento na transição agroambiental: em defesa da pluralidade epistemológica e metodológica na prática científica. Cadernos de Ciência \& Tecnologia, Brasília, v. 17, n. 3, p. 29-57, set./dez. 2000.

DYER, J. E.; HASSE-WITTLER, P. S.; WASHBURN, S. G. Structuring agricultural education research using conceptual and theoretical frameworks. Journal of Agricultural Education, v. 44, n. 2, p. 61-74, 2003.

FIGAREDO CURIEL, F. La tradición cienciológica en el estudio de la ciencia. Llull: Revista de la Sociedad Española de Historia de las Ciencias y de las Técnicas, Zaragoza, v. 25, n. 54, p. 621-642, 2002.

FREYRE ROACH, E. F.; RAMOS LAMAR, A. Ciencias Agrarias y Sociedad. In: NÚÑEZ JOVER, Jorge. Problemas sociales de las ciencias y las tecnologías. C. Habana: Editorial Félix Varela, 1994. p. 15-28.

FUNES-MONZOTE, F. R. et al. Transformando el campo cubano: avances de la agricultura sostenible. La Habana: Asociación de Técnicos Agrícolas y Forestales; Editorial Asociación Cubana de Técnicos Agrícolas y Forestales, 2001.

FUNES-MONZOTE, F. R. Agricultura con futuro. La alternativa agroecológica para Cuba. Matanzas/Cuba: Estación Experimental "Indio Hatuey” / Universidad de Matanzas, 2010.

GOMES, J. C. C. Pluralismo metodológico en la producción y circulación del conocimiento agrario: fundamentación epistemológica y aproximación empirica a casos del sur de Brasil. 1999. 360 p. Tese (Doutorado em Sociologia) - Instituto de Sociología y Estudios Campesinos, Universidad de Córdoba, Córdoba, 1990.

HABERMAS, J. Conhecimento e Interesse. Rio de Janeiro: Zahar Editores, 1982.

JACOB, L. B. Agroecologia na universidade: entre vozes e silenciamentos. Curitiba: Appris, 2016.

KUHN, T. S. A estrutura das revoluções científicas. São Paulo: Perspectiva, 1978.

LEFF, E. Sustentabilidad y racionalidad ambiental: hacia "otro" programa de sociología ambiental. Revista Mexicana de Sociología, Mexico, v. 73, n. 1, p. 5-46, jan./mar. 2011.

LÓPEZ, T. Organización y estructura del sistema de extensión agraria (SEA) en Cuba. Revista Computarizada de Producción Porcina, v. 12, n. 1, 2005.

LOVE, G. M. An Introduction to the Philosophy of Agricultural Education. Journal of the Association of Teachers Educators in Agriculture, v. 19, n. 1, p. 2-10, 1978.

MACHÍN SOSA, B. et al. Revolución agroecológica: el Movimiento de Campesino a Campesino de la ANAP de Cuba. La Habana: ANAP, 2010

MILLER, LARRY E. A philosophical framework for agricultural education research. Journal of Agricultural Education, v. 47, n. 2, p.106-117, 2006. 
SÁNCHEZ GAMBOA, S. A. Projetos de pesquisa, fundamentos lógicos: a dialética entre perguntas e respostas. Chapecó/Santa Catarina: Argos, 2013.

SERRA BORSATTO, R.; SIMÕES DO CARMO, M. Agroecologia e sua epistemología. Interciencia, Asociación Interciencia Caracas, Venezuela, v. 37, n. 9, p. 711-716, set. 2012,

\section{Como citar este artigo:}

ROACH, Eduardo Francisco Freyre.; LAMAR, Adolfo Ramos. Educação científica e realidade em Cuba: algumas ideias sobre sua mudança epistemológica. Revista Ibero-Americana de Estudos em Educação, Araraquara, v. 14, n. 3, p. 928-941, jul./set., 2019. e-ISSN: 1982-5587. DOI: $10.21723 /$ riaee.v14i3.11530

Data de Submissão: 05/07/2018

Revisões requeridas: 10/08/2018

Aceite em: 10/10/2018

Publicado em: 23/03/2018 